\title{
GENETICS OF FRAGMENT CHROMOSOMES IN TRILLIUM GRANDIFLORUM
}

\author{
ALFRED RUTISHAUSER \\ Institut für allgemeine Botanik, Universität Zürich
}

Received 23.ii. 56

\section{SUPERNUMERARY CHROMOSOMES}

A CONSIDERABLE number of organisms exhibit, as well as the normal chromosomes of the diploid chromosome set, B-chromosomes which behave in an irregular manner partly from a morphological point of view, but more often from the physiological. Although it is usually easy to distinguish between the B- and the ordinary or A-chromosomes, there are many difficulties in the way of finding features which are characteristic of all known B-chromosomes.

Oestergren (1945) tried to find a universally valid definition by grouping together all known characteristics of B-chromosomes. But he himself points out that no single B-chromosome possesses all the characteristics mentioned.

B-chromosomes clearly represent an extraordinary divergent group of chromosome bodies, and at present it is not easy to see how, for example, the big gap between the accessory chromosomes of Godetia viminea (Hakkansson, 1949, I950) and the B-chromosomes of Zea Mays (Randolph, I94I) can be bridged. Further extensive research is necessary to clarify the origin and function of these interesting chromosomes.

The present work is a report on several experiments which were made with the particular object of investigating the distribution of fragment chromosomes of Trillium grandiflorum. The results obtained throw some light on their distribution during the heterotypic division of the EMC. Because of the great difficulties of breeding from Trillium, the investigations into fragment chromosomes were undertaken with hybrid endosperms. Because one of the ordinary chromosomes of T. grandiflorum is termed a "B-chromosome", we are forced to use the expression " fragment" for the supernumerary chromosomes.

\section{MATERIAL AND METHODS}

The test-plants, 75 specimens of $T$. grandiflorum and 3 of $T$. luteum were taken from three nurseries-A. Vogt, Erlenbach; C. Frickart Söhne, Stäfa/Zürich (both classified G) and B. Ruys, Dedemsvaart/Holland (GH). The plants from all three sources proved to be highly self-sterile.

To obtain information about the heterochromatin content, all plants were exposed to a temperature of $0 \cdot 3^{\circ}$ to $\mathrm{I} \cdot 0^{\circ} \mathrm{C}$. for four days. This was before fixation. five or six weeks after pollination. My experiments show that this treatment is sufficient to obtain maximum starvation effect with normal chromosomes of root tip and endosperm mitosis.

After the exposure to cold the seeds are taken out of the fruit, fixed in Carnoy and then transferred to 80 or 90 per cent. alcohol. In this fluid, the seeds can be 
kept up to three weeks at a temperature of $0^{\circ} \mathrm{C}$. without the chromosomes losing their staining capacity. After the hydrolysis (six to ten minutes in $n \mathrm{HCl}$ at $6 \mathrm{o}^{\circ} \mathrm{C}$.) and staining in leuco-basic fuchsin the endosperms can easily be extracted from the seeds with the help of two needles. As Feulgen-stain often penetrates slowly, it is recommended that the seeds be taken out of the staining solution after two hours and left in tap water for two or three hours. Staining with Orcein has also proved useful.

\section{RESULTS OF THE EXPERIMENTS}

As is shown in table $\mathrm{I}$, plants with fragments appear in both samples of $\mathcal{T}$. grandiflorum $(2 n=\mathrm{I}$ ) $)$. Of 54 plants from the $\mathrm{G}$-sample, ro specimens contained one and two contained two fragments.

TABLE I

Fragment chromosomes in $\mathrm{T}$. grandiflorum and $\mathrm{T}$. luteum

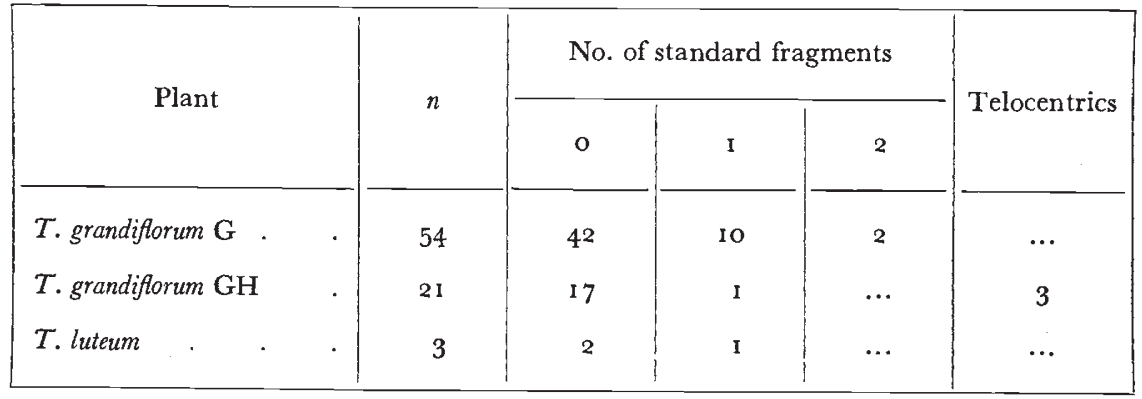

All the fragments in this first experimental group were morphologically identical apart from minor differences of size. They possess a submedian centromere, the shorter arm measures $0.9 \mu$ on the average, the longer one I $3 \mu$ (text-fig. I $a$; plate, fig. I). No signs of heterochromatin could be discovered. The staining even after prolonged cold treatment (4-5 days in $\pm 0^{\circ} \mathrm{C}$.) coincides completely with the staining of the euchromatic regions of the ordinary chromosomes. Additional heteropycnotic spots in the resting nucleus could not be discovered. The fragments of the G-plants are, therefore, completely euchromatic. We term them hereafter standard fragments $(f r)$.

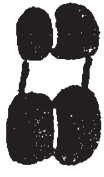

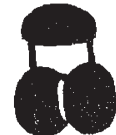

$b$

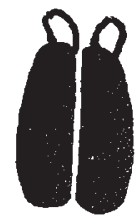

C

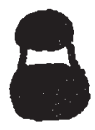

d

TeXt-FIG. I.-Fragment chromosomes; $a, b$, standard fragments from $T$. grandiflorum $(a, \mathrm{G}, \vec{b}, \mathrm{GH}) ; c$, telocentric ; $d$, standard fragment from $\mathcal{T}$. luteum. $\quad \times 5500$.

The fragments of the second experimental group were also purely euchromatic. But here two different kinds of $f r$-chromosomes appeared. One kind (text-fig. Ib) coincides with the standard fragment of the 
G-group. The centromere of the other kind, however, seems to be terminal (text-fig. I $c$; plate, fig. 2) even in the best preparations. No trace of a second shorter chromosome arm could be found. Numerous measurements have shown that their centromere region is of the same length as that of the standard fragments. I am, therefore, of the opinion that here it is a question of genuine telocentric chromosomes $(t)$. The length of its arm is $3.5 \mu$. It is considerably bigger than the sum of the arms of the standard fragment. Therefore, it does not seem probable that they have resulted from a break at the centromere followed by reunion of the shorter and longer arms of the standard fragment.

The distribution of both types of chromosomes, the standard fragment and the telocentric chromosome, in the mitosis of the root tips and the endosperms is completely normal. No somatic nondisjunction could be found.

The $f r$-chromosomes of $T$. luteum $(2 n=10)$ correspond morphologically to the standard type of $T$. grandiflorum (text-fig. I $d$ ). They too are purely euchromatic and possess a submedian centromere. The length of the two arms is on an average smaller. They are $0.5 \mu$ and $\mathrm{I} \cdot 0 \mu$ respectively.

\section{DISTRIBUTION OF FRAGMENT CHROMOSOMES \\ IN THE ENDOSPERMS}

The distribution of the $f r$-chromosomes could only be exactly ascertained in the standard fragment of $T$. grandiflorum. In 18 experimental plants crossbreedings of the type $\mathrm{O} \times f r, f r \times \mathrm{O}$ and $f r \times f r$ was

TABLE 2

Distribution of fragment chromosomes in $F_{1}$-endosperms

\begin{tabular}{|c|c|c|c|c|c|c|c|c|}
\hline \multirow{2}{*}{\multicolumn{2}{|c|}{ Cross }} & \multirow{2}{*}{$\begin{array}{l}\text { No. of } \\
\text { crosses }\end{array}$} & \multicolumn{4}{|c|}{$\begin{array}{l}\text { No. of fragments } \\
\text { in endosperms }\end{array}$} & \multirow{2}{*}{$n$} & \multirow{2}{*}{$\begin{array}{c}\text { fr per } \\
\text { endosperm }\end{array}$} \\
\hline & & & $\mathbf{o}$ & I & 2 & 3 & & \\
\hline \multicolumn{9}{|c|}{ 1. Standard fragments } \\
\hline$O \times f r$ & & 16 & 166 & 183 & $\cdots$ & ... & 349 & 0.5 \\
\hline$f_{r} \times 0$ & & 6 & 27 & 2 & 175 & 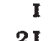 & 205 & $1 \cdot 7$ \\
\hline$f r \times f r$ & • & 4 & 5 & 3 & 33 & 21 & 02 & $2 \cdot 1$ \\
\hline \multicolumn{9}{|l|}{ 2. Telocentrics } \\
\hline & • & 1 & 2 & $\cdots$ & 2 & $\cdots$ & 4 & $\cdots$ \\
\hline
\end{tabular}

carried out, and the number of $f r$-chromosomes in $\mathbf{F}_{1}$-endosperms was investigated with squash preparations (plate, figs. 3-5). The results of these investigations are reproduced in table 2.

The cross $\mathrm{O} \times f r$ gave a normal I : I distribution. The deviation is not significant $(\mathrm{P} \geqslant 0 \cdot 5)$. In agreement with Sparrow's statements (1952) about the behaviour of the $f r$-chromosomes in the meiosis of 
T. erectum it can be stated that the distribution of the fragments in the microspores is regular. During pollen grain-development nondisjunction does not occur or is very rare.

On the other hand, the distribution of the standard fragments on the female side deviates noticeably from the ratio I : I. As the endosperm nuclei are made up of two polar nuclei and one sperm nucleus, we would expect endosperms without standard fragments and those with two standard fragments in equal numbers. Instead of this, there was a considerable predominance of 2 fr-endosperms. As the $\chi^{2}$-test shows, the deviation from the I : I ratio is significant $(\mathrm{P}<0.00 \mathrm{I})$.

That this distribution is not accidental is further proved by the results of crosses carried out on plants which contained a fr-chromosome each. In the $f r \times f r$-crosses, the endosperms with and without a $f r$-chromosome correspond to the $\mathrm{O}$-endosperms of the $f r \times \mathrm{O}$-cross, the endosperms with 2 or 3 fr-chromosomes respectively correspond with the $2 f r$-endosperms. The frequency of the last two categories is $87 \cdot 1$ per cent. and is almost exactly the same as the frequency of the two $f r$-endosperms in the $f r \times \mathrm{O}$-cross $(85.9$ per cent.). Therefore, there can be no doubt that distribution of the standard fragments in male and female gametes does not take place according to the same laws.

The question arises how the uneven distribution of standard fragments in the ovules occurs. Although no investigations into the embryo sac-development of Trillium plants with such chromosomes have been carried out, their behaviour during meiosis can be inferred. First it must be remembered that the embryo sacs of $T$. grandiflorum develop according to the Allium-type (Ernst, I902). After the heterotypic division of the EMC 2 dyad cells appear. One of these, the micropylar, degenerates, while the chalazal dyad cell without further division develops into the nuclear embryo sac.

From the development of the embryo sac of $T$. grandiflorum it can be seen that the deviation from the ratio $I: I$, as found in the distribution of standard fragments in the endosperms of $f r \times \mathrm{O}$ - and $f r \times f r$ crosses, can only be due to the fact that the univalent $f r$-chromosomes are irregularly distributed during the first meiotic division. According to Sparrow (1952), the unpaired $f r$-chromosomes of $T$. erectum remain undivided in the first division. They do not split until the anaphase of the second division. Assuming that the univalents behave in the same way in the meiosis of the EMG of $T$. grandiflorum, the conclusion can be drawn that their movement during the first division is directed. More standard fragments move to the chalazal than to the micropylar pole. By regular distribution of the split halves into the two nuclei of the two-nuclear embryo sac (second division) only nuclei with fragments arise in the female gametes. So it can be understood why two standard fragments were found in most endosperms.

The preponderance of dyads with standard fragments would also be comprehensible if we assume that their split takes place at least 
in part in the second division as Bosemark (1954) states in connection with Festuca pratensis and Fernandes (1946) with Narcissus bulbocodium. But as mostly endosperms with two standard fragments appear, it would further have to be assumed that all fragment chromosomes split in the second meiotic division again. Such behaviour is assumed by Fernandes (1946) for single B-chromosomes of Narcissus bulbocodium. Apart from the fact that this conclusion was arrived at only indirectly (from the distribution of heterochromatin in the resting nucleus of the microspores), the assumption of an occasional additional division of univalents in the second meiotic division is not sufficient to explain the frequent appearance of endosperms with two standard fragments. Therefore, I keep to my first assumption.

Unfortunately, the genetics of telocentrics could not be investigated thoroughly. All three experimental plants with such chromosomes were weakly and only one flowered. In the one fruit obtained only six seeds developed. In four endosperms of the $f r \times \mathrm{O}$-cross the number of telocentrics could be ascertained. Two were free of them, and two had two telocentrics each. Plate, fig. 6 shows a metaphase

TABLE 3

Seed fertility of T. grandiflorum

\begin{tabular}{|c|c|c|c|c|c|}
\hline Cross & $\begin{array}{l}\text { No. of } \\
\text { fruit }\end{array}$ & $\begin{array}{l}\text { Well- } \\
\text { developed } \\
\text { seeds }\end{array}$ & $\begin{array}{l}\text { Degenerate } \\
\text { seeds }\end{array}$ & $\begin{array}{l}\text { Seed } \\
\text { fertility }\end{array}$ & $\begin{array}{c}f r \text { per } \\
\text { endosperm }\end{array}$ \\
\hline $\begin{array}{l}\mathrm{O} \times \mathrm{O} . \\
\mathrm{O} \times f r . \\
f r \times \mathrm{O} . \\
f r \times f r .\end{array}$ & $\begin{array}{r}12 \\
20 \\
6 \\
4\end{array}$ & $\begin{array}{r}220 \\
600 \\
198 \\
82\end{array}$ & $\begin{array}{r}168 \\
202 \\
90 \\
23\end{array}$ & $\begin{array}{l}56 \cdot 7 \text { per cent. } \\
74 \cdot 8 \quad, \\
68 \cdot 8 \quad, \\
78 \cdot 1 \quad "\end{array}$ & $\begin{array}{l}0 \cdot 0 \\
0 \cdot 5 \\
1 \cdot 7 \\
2 \cdot 1\end{array}$ \\
\hline
\end{tabular}

with $6 n=30$ chromosomes which was caused by the duplication of the triploid chromosome number $3^{n}=15$ (a process which occurs relatively often in endosperms) and in which four telocentrics can clearly be seen.

While the telocentrics seem to have a detrimental influence, the standard fragments in the quantity observed appear to have a favourable effect on the seed fertility.

Table 3 summarises the results of counts which were made of the seeds of six- to seven-weeks-old fruits of $T$. grandiflorum. They show that there is a slight increase in the number of well developed seeds in fruits of the crosses $\mathrm{O} \times f r, f r \times \mathrm{O}$ and $f r \times f r$. But it must be stated that the ordinary chromosomes of several plants which are used in these crosses vary in their heterochromatin content. The heterochromatin seems to have some influence on the seed fertility. This and the most striking effect of the fr-chromosomes of $T$. grandiflorum, their ability of promoting spontaneous chromosome breakage, will be discussed in another paper. 


\section{DISCUSSION}

In Trillium fragment chromosomes were first discovered by Sparrow, Pond and Sparrow (1952) in T. erectum, and their behaviour during meiosis and pollen development was investigated. According to Sparrow's statements, they can be regarded generally as fairly normal. In the first meiotic division they move undivided to one of the two poles and split in the second division. Loss of fragment chromosomes through lagging occurs, but is relatively rare. So in plants with only one fragment chromosome, the values found for microspores with and without a fragment deviate slightly from the ratio I : I. Microspores without fragments are somewhat more frequent.

The results of the cross experiments which were carried out on T. grandiflorum partly agree with Sparrow's findings. The cross $\mathrm{O} \times f r$ produced endosperms with and without fragment chromosomes in the ratio I : I (table 2). But, surprisingly, the reciprocal cross $f r \times \mathrm{O}$ leads to quite a different result : the number of endosperms with two standard fragments is considerably higher than would be expected with random distribution $(85.9$ per cent. instead of 50 per cent.). The same result was given by the $f r \times f r$-cross. As has been stated in full above (p. 198), this finding can be best understood if it is assumed that the univalent standard fragments mostly move towards those dyads which later form the embryo sac. Their movement in the first meiotic division of the EMC is, therefore, directed.

It can be stated that there is a distant similarity between the distribution described for $T$. grandiflorum and for the acrocentric B-chromosomes of Trimerotropis sparsa and Circotettix thalassium. According to White (1954), univalent B-chromosomes are distributed at random in spermatogenesis, but bivalent B-chromosomes often group themselves in such a manner on the spindle that both partners move towards the same pole. In this way, gametes are formed with two $\mathrm{B}$-chromosomes and without any.

The abnormal behaviour of the standard fragments in the $f r \times \mathrm{O}$ and $f r \times f r$-crosses indicates that the conditions to which they are subject in the PMC and EMC are somewhat different. While ordinary chromosomes (which, of course, pair regularly) are distributed evenly in both cell types, the difference is big enough to influence the distribution of the fragment chromosomes. As the standard fragments of $T$. grandiflorum are purely euchromatic, the heterochromatin is eliminated as a possible factor in the irregular course of the first meiosis. It is, therefore, very probable that the centromere has something to do with the difference. Unlike Sparrow (I952), my conclusion is that the centromere is not quite normal. Some weight is given to this finding because of Fernandes' assumption (1946) that the heterochromatisation of B-chromosomes in Narcissus bulbocodium resulted in a weakening of the centromere. In the standard fragment of $T$. grandiflorum no connection can be found between the chromatin type and the physiology of the centromeres. 
An interesting consequence of the irregular distribution of standard fragments in the meiosis of the EMC is that there is an increase in their number in the endosperms of $f r \times \mathrm{O}$ - and $f r \times f r$-crosses. If one assumes that embryos of endosperms with one or two standard fragments all contain I $f r$ and embryos of endosperms with 3 standard fragments contain 2, the inference is that the average fragment content in the embryos of these crosses is higher than that in the parents. For the two crosses $f r \times \mathrm{O}$ and $f r \times f r$ it amounts to $0 \cdot 86$ and $\mathrm{I} \cdot 26$ respectively instead of 0.5 and $I \cdot O$ respectively. In spite of the failure of non-disjunction in the pollen grain mitosis, the result should, therefore, be an increase of their numbers in the $F_{1}$-generation. One may, therefore, suppose that the fragments of $T$. grandiflorum maintain or even increase their numbers in a population.

Thus, the directed distribution of standard fragments in the meiosis, like non-disjunction, shows a special mechanism which favours their propagation. It is not known whether this is counteracted by an opposing process as is the case with Secale cereale (Müntzing, I943), where lagging results in a considerable loss of accessory chromosomes at meiosis and where, as the number of such chromosomes increases, the seed fertility is lowered. The $f r \times f r$-crosses produced about the same percentage of good seeds as the $\mathrm{O} \times f r$-crosses. Fertility tests with plants with more fragment chromosomes have not yet been made.

In their tendency to maintain themselves within a population, the standard fragments of $T$. grandiflorum resemble the B-chromosomes of Zea Mays, Secale cereale, Anthoxanthum aristatum and Festuca pratensis. It is only the mechanism which produces this result that is different.

As to the chromaticity, considerable differences exist between the B-chromosomes of the plants hitherto investigated. The B-chromosomes of Zea Mays (Darlington and Upcott, I94I), Anthoxanthum aristatum (Oestergren, I947) and Festuca pratensis (Bosemark, I954) are distinctly heterochromatic. The B-chromosomes of Sorghum purpurascens (Darlington and Thomas, I94I), Poa alpina (Håkansson, I948), Narcissus bulbocodium (Fernandes, I 946), Centaurea scabiosa (Fröst, I948) and all the accessory chromosomes in mosses noted by Vaarama, (I949, I950, I953) have also been designated heterochromatic. Whether this is also true of Secale cereale does not seem to be certain. Müntzing (I95I) is of the opinion that the accessory chromosomes of this species are not heterochromatic or, at least, not clearly so, but he adds that the standard fragments, according to the investigations of Lima de Faria, contain more regions of special appearance in proportion to their length than the A-chromosomes.

Darlington and La Cour (1938) were the first to show with fragment chromosomes of Paris polyphylia that the B-chromosomes can be purely euchromatic also. The same is also true for the B-chromosomes of Caltha palustris (Reese, I954) and Godetia viminea (Håkansson, I949). 
After Sparrow (1952) had drawn attention to the euchromatic nature of the fragments of $T$. erectum, I succeeded in showing that in T. grandiflorum and $T$. luteum, even after prolonged cold treatment (4-5 days in a temperature of $\pm 0^{\circ} \mathrm{C}$.), there was no sign of any difference in staining between standard fragment and euchromatic ordinary chromosomes. Thus, the fragment chromosomes of the Trillium species, too, contain no visible heterochromatin. These findings have some significance with regard to the abnormal behaviour of the standard fragments in the course of meiosis and, especially, because of their genetic activity. It has already been shown that the standard fragments of $T$. grandiflorum tend to maintain themselves within a population as well as the heterochromatic B-chromosomes of maize and rye. But in respect of the genetic activity, too, there appears to be no essential difference, as far as present experimental results permit such a conclusion.

According to my investigations the seed fertility seems to be favourably influenced by the introduction of up to three euchromatic standard fragments in the endosperm. Favourable effects are described for heterochromatic B-chromosomes as well. From Fröst's measurements of plant weight of Centaurea scabiosa (cit. from Müntzing, r 954) the presence of a few B-chromosomes seems to be more advantageous than their complete absence and Roman (1947) found in maize forward growth of pollen tubes which contained heterochromatic B-chromosomes.

Whether euchromatic B-chromosomes can also have an unfavourable effect is not yet known. Still it must be noted that all samples of T. grandiflorum that had euchromatic telocentrics were weak and rarely flowered.

\section{SUMMARY}

I. Plants of Trillium grandiflorum and $T$. luteum have been found with one to two small euchromatic fragment chromosomes, the centromere of which is either submedian (standard fragments, $f r$ ) or terminal (telocentrics).

2. Crosses of the type $\mathrm{O} \times f r, f r \times \mathrm{O}$ and $f r \times f r$ show that distribution of single standard fragments is normal ( $\mathrm{I}$ : I ratio) if the male plant alone carries the fragment. When it is carried on the female side, however, there is a preponderance of endosperms with two to three fragments (see table 2).

3. It is assumed that there is a directed movement of univalent fragments at meiosis in EMC toward the dyad cell which forms the embryo sac. This would appear to be another mechanism for the maintenance of B-chromosomes in wild populations.

Acknowledgments. The first research for this paper was begun in the cytological laboratory of the John Innes Horticultural Institution and then continued in Schaffhausen with the support of the Swiss National Fund. I am deeply indebted to Professor C. D. Darlington, formerly director of the John Innes Horticultural 


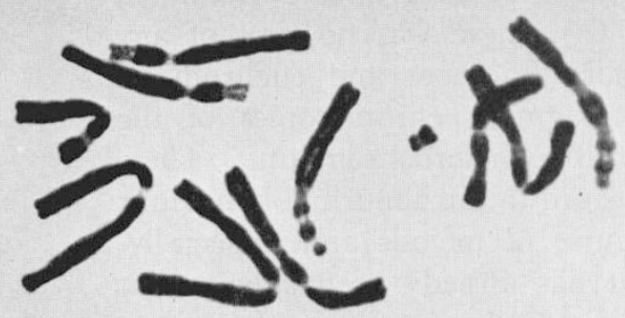

I Atate

2
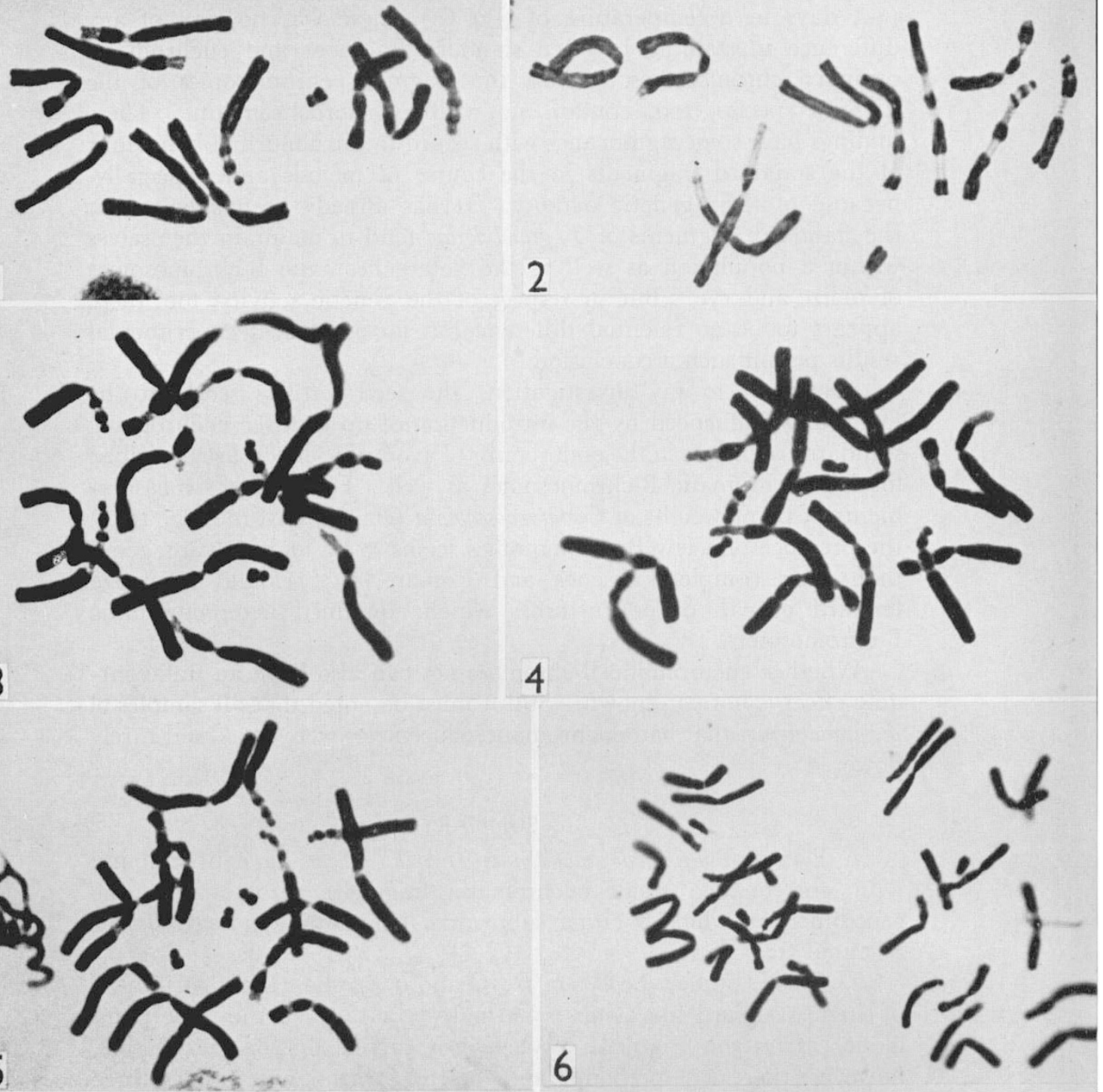

5

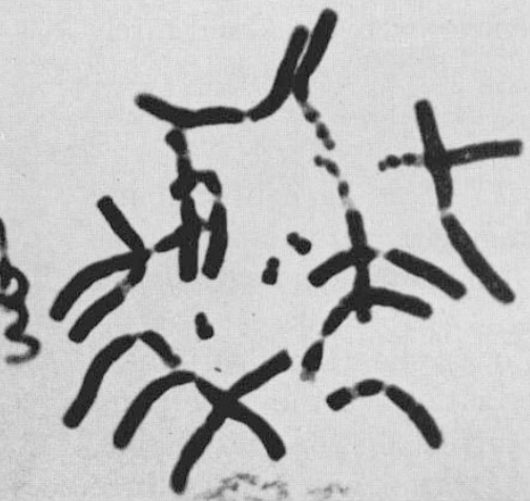

FIG. I. - Metaphase of root-tip cell with standard fragment. $\times$ Iooo.

Fig. 2.- - Metaphase of root-tip cell with telocentric. $\times$ I ooo.

FIG. 3.- Metaphase of endosperm with one standard fragment. $\times 900$.

Fig. 4.-Metaphase of endosperm with 2 standard fragments. $\times 900$.

Frg. 5.-Metaphase of endosperm with 3 standard fragments. $\times 900$.

Fig. 6. - Hexaploid metaphase of endosperm with 4 telocentrics (2 chromosomes cut). $\times 5^{00}$. 
Institution, for many suggestions, and to Mr L. F. La Cour, M.B.E., for his criticism and valuable technical help. Special thanks go to my assistant, Miss Jolanda Botta, for conscientious cooperation, and to Mr A. K. McGill for the translation of the manuscript.

\section{REFERENCES}

Bosemark, N. O. 1954. On accessory chromosomes in Festuca pratensis. 1. Cytological investigations. Hereditas, $4^{0}, 346-376$.

bosemark, N. O. I954. On accessory chromosomes in Festuca pratensis. 2. Inheritance of the standard type of accessory chromosomes. Hereditas, $4^{\circ}$, 425-437.

Darlington, c. D. I940. The origin of iso-chromosomes. F. Genet., 39, 351-36o.

DARLINGTON, G. D., AND LA COUR, L. F. 1938 . Differential reactivity of the chromosomes. Ann. Bot., 2, 615-625.

DARLington, C. D., AND THOMAS, P. T. 1941. Morbid mitosis and the activity of inert chromosomes in Sorghum. P.R.S., Ser. B, I30, 127-150.

DARLINGTON, G. D., AND UPCOTT, M. B. 194I. The activity of inert chromosomes in Zea Mays. F. Genet., 4I, 275-296.

ERNST, A. I902. Chromosomenreduktion, Entwicklung des Embryosacks und Befruchtung bei Paris quadrifolia L. und Trillium grandiflorum Salsb. Flora, gI, $\mathrm{I}-46$.

FERNANDES, A. 1946. Sur le comportement des chromosomes surnuméraires hétérochromatique pendant la méiose. I. Chromosome long hétérobrachiaire. Bol. Soc. Brot., 20, 93-138.

FRöst, s. 1948. B and ring chromosomes in Centaurea scabiosa. Hereditas, 34, $255-256$.

HẢKANSSON, A. I948. Embryology of Poa alpina plants with accessory chromosomes. Hereditas. 34, 233-247.

HÅKANSSON, A, 1949. Supernumerary chromosomes in Godetia viminea. Hereditas, $35,375-389$.

HÅKANSSON, A. 1950. Spontaneous chromosome variation in the roots of a species hybrid. Hereditas, 36, 39-59.

LONGLEY, A. E. 1927. Supernumerary chromosomes in Zea Mays. F. Agric. Research, 35, 669-784.

MATHER, K. 1944. The genetical activity of heterochromatin. P.R.S., Ser. B, 132, 308-332.

MÜNTZING, A. I943. Genetical effects of duplicated fragment chromosomes in rye. Hereditas, 19, 9 I - I 10.

MÜNTZING, A. 1944. Cytological studies of extra fragment chromosomes in rye. I. Iso-fragments produced by misdivision. Hereditas, 30, 23 I-248.

MÜNTZING, A. 1945. 2. Transmission and multiplication of standard fragments and iso-fragments. Hereditas, $31,457-477$.

Müntzing, A. 1951. The meiotic pairing of iso-chromsomes in rye. Port. Acta Biol., Ser. A, Goldschmidt-Vol., 83 I-86o.

müntZING, A. 1954. Cyto-genetics of accessory chromosomes (B-chromosomes). Proc. of the gth Int. Congress of Genetics, Part I, 282-30 I, Carologia, Vol. VI, Suppl., Firenze 1954.

MÜNTZING, A., AND LIMA DE FARIA, A. 1953. Pairing and transmission of a small accessory iso-chromosome in rye. Chromosoma, $6,14^{2-1} 4^{8}$.

oestergren, G. I945. Parasitic nature of extra chromosomes. Bot. Not., 1 945, I57-163.

OesterGReN, G. 1947. Heterochromatic B-chromosomes in Anthoxanthum. Heriditas, 33, 36 I -396 .

RANDOLPH, L. F. I94I. Genetic characteristics of the B-chromosomes in maize. Genetics, 26, 608-63I.

REESE, G. 1954. Euploidie, Aneuploidie und B-Chromosomen bei Caltha palustris L. Planta, 44, 203-268. 
ROMAN, H. 1947. Mitotic nondisjunction in the case of interchanges involving the B-type chromosome in Maize. Genetics, 32, 391-409.

RUTISHAUSER, A. 1954. Das Verhalten der Chromosomen in arteigener und artfremder Umgebung. Vierteljahrsschrift der Naturforsch. Ges. Zürich, C, I955, I 7-26.

SPARROW, A. H., POND, V., AND SPARROW, R. C. 1952. Distribution and behaviour of supernumerary chromosomes during microsporogenesis in a population of Trillivm erectum L. The American Naturalist, 86, 277-292.

vaArama, A. 1949. Meiosis in moss-species of the family Grimmiaceae. Port. acta biolog., Ser. A, Goldschmidt-Vol., 47-78.

VAarama, A. 1950. Studies on chromosome number and certain meiotic figures of several Finnish moss-species. Bot. Not., 1950, 239-256.

VAarama, A. 1950. Accessory iso-chromosomes in the moss Dicranum majus. Nature, 165,894 .

VAARAMA, A. 1953. Chromosome fragmentation and accessory chromosomes in Orthotrichum tenellum. Hereditas, 39, 305-316.

whIтE, м. J. D. 1954. Animal Cytology and Evolution. Cambridge. 